\title{
THE EFFECT OF REFLEXOLOGY IN INTENSITY OF PAIN AND ANXIETY AMONG PATIENTS SUFFERING FROM METASTATIC CANCER IN ADULTS' HEMATOLOGY WARD
}

\author{
SIMIN JAHANI ${ }^{1}$, FATEMEH SALARI ${ }^{1 *}$, NASRIN ELAHI ${ }^{2}$, BAHMAN CHERAGHIAN ${ }^{3}$
}

${ }^{1}$ Department of Nursing, Nursing Care Research Center in Diseases, Ahvaz Jundishapur University of Medical Sciences, Ahvaz, Iran. ${ }^{2}$ Department of Nursing, Nursing and Midwifery School, Ahvaz Jundishapur University of Medical Sciences, Ahvaz, Iran. ${ }^{3}$ Department of Statistics and Epidemiology, School of Public Health, Ahvaz Jundishapur University of Medical Sciences, Ahvaz, Iran. Email: fatemeh.salari63@yahoo.com

Received: 08 February 2017, Revised and Accepted: 26 March 2018

\section{ABSTRACT}

Introduction: Findings suggest dissatisfaction of half of the cancer patients regarding pain and anxiety management. This study aimed to determine the effect of reflexology on the intensity of pain and anxiety among patients with metastatic cancer hospitalized in adult hematology ward.

Methods: In this study, the samples were selected from adult hematology ward in Baghaei 2 hospital in Ahvaz, Iran, according to the inclusion criteria. They were then assigned into treatment and control groups. In the treatment group, reflexology protocol was performed following manual reflexology method by Fr Josef Eugster based on Ingham method on the patient's bed. In the control group, sole touching was used as the placebo. Reflexology was performed for three days, $30 \mathrm{~min}$ per day. Spielberger questionnaire were provided to the samples and completed in the first and third days, and Spielberger questionnaire was provided to the samples and completed. The data obtained from this study were then analyzed by SPSS 20.

Results: The two groups did not show a significant difference in terms of demographic characteristics ( $>>0.05)$. Based on the obtained results, it was found that in the test group, there was a significant difference between the mean intensity of pain before and after the treatment across all 3 days as well as the mean anxiety of the $1^{\text {st }}$ and $3^{\text {rd }}$ days $(\mathrm{p}<0.05)$. However, in the control group, there was no significant difference in terms of mean pain intensity before and after the treatment across 3 days $(p>0.05)$. No significant difference was observed between the mean anxiety of the $1^{\text {st }}$ and $3^{\text {rd }}$ days either $(\mathrm{p}>0.05)$.

Conclusion: Considering the findings of this research, it can be concluded that reflexology has a positive effect on mitigating the intensity of pain and anxiety in metastatic cancer patients. Therefore, it is recommended that nurses employed in cancer centers benefit from the findings of this research to further help patients with cancer. It is also suggested that further research be conducted on the effect of reflexology on the pain and anxiety of other patients.

Keywords: Reflexology, Pain, Anxiety, Cancer.

(c) 2018 The Authors. Published by Innovare Academic Sciences Pvt Ltd. This is an open access article under the CC BY license (http://creativecommons. org/licenses/by/4. 0/) DOI: http://dx.doi.org/10.22159/ajpcr.2018.v11i6.25212

\section{INTRODUCTION}

Cancer is one of the major health problems and accounts for $12 \%$ of deaths around the world. In the past few decades, the incidence of cancer and its associated mortality have increased considerably, such that cancer is the second common cause of death in developed countries, and the third cause in less developed countries [1,2]. In 2006, the incidence of cancer in Iran was estimated to be 70000 cases, where every day, 98 Iranian people die due to this disease. Now, with the increasing percentage of the elderly in the country, it is expected that in the future years, the incidence of cancers will grow significantly [3].

Pain is the most common symptom in patients with cancer, adversity influencing the quality of life of people in physical, mental, social, and spiritual dimensions [4]. The pain resulting from cancer is multidimensional and complex, and its understanding for the health of individuals is inconceivable [5,6]. Pain in these people develops numerous health problems and not merely in physical dimensions. Rather, it creates mental problems including anxiety and depression [7].

Anxiety is one of the mental components adversely affecting the quality of life [8,9]. Various factors can cause anxiety during the course of this disease. Diagnosis of cancer itself is a strong stressor factor bringing about diminished self-confidence, anxiety, and depression $[5,10]$. Considering the recent advances in healthcare, pain, and anxiety management of cancer has still remained a major challenge. Findings indicate that pain management in cancer is not satisfactory and half of cancer patients suffer from this unpleasant feeling, whereby the maximum anxiety experienced in patients is due to pain [7]

In cancer pain management, pharmacological and non-pharmacological tools are used [11]. Although in the western medicine (employing pharmacotherapy and manipulating the main structure of the human body) it is considered the main tool for pain management in cancer patients, complementary and alternative medicine can also be highly effective to improve the state of pain and anxiety in cancer patients $[12,13]$. One of the pain mitigation methods in complementary medicine is reflexology [14]. Reflexology causes simulation of nervous and hormonal system through increased blood supply, increased waste disposal such as lactic acid, and stimulation of reflexive points. For physical, mental, and spiritual balance, it causes mitigated fatigue, pain, and anxiety, thus improving quality of life $[13,15]$.

A number of studies have been conducted regarding the effect of reflexology on pain and anxiety among cancer patients. The findings of these studies suggest that reflexology in patients with breast and lung cancer causes diminished pain and anxiety and decreased pain in metastatic cancer patients $[16,17]$. It has also led to lowered anxiety [18] in patients suffering from non-metastatic cancers undergoing chemotherapy. In the available studies, further research has been recommended to be conducted on this group of patients with a larger sample volume [16]. 
Reflexology technique is simple and is a readily available everywhere without requiring any special equipment. It is also considered a noninvasive method and does not interfere with other therapeutic methods that the patient may receive [16]. The notable point is that none of these studies have reported unfavorable side effects for reflexology [5]. Eventually, considering the high prevalence and incidence of cancer in the society and the debilitating effects of pain and anxiety in the quality of patients suffering from cancer and the complications mentioned for key chemotherapeutic agents, the necessity of developing complementary medicine, especially reflexology to control pain in this group of patients, is strongly felt. Accordingly, this study aims to determine the effect of reflexology on patients with metastatic cancer hospitalized in adult hematology ward of Baghaei 2 hospital in Ahwaz, Iran.

\section{METHOD}

This study is a single-blind clinical trial, in which the studied people were not aware of being assigned in the test or control groups. Following obtaining the ethics code (IR.AJUMS.REC.1395.669) IRCT2017061634381N2 the permission of authorities in Baghaei 2 hospital in Ahvaz, the researcher entered the adult hematology ward of the hospital and selected the samples according to the inclusion criteria. After introducing himself and the objective of the study and obtaining written consent, he then assigned them into control and treatment groups using six-block method randomly.

To determine the sample volume, the formula for comparing two ratios $\mathrm{n}=\frac{\left(\mathrm{z}_{1- \pm / 2 \text { 酒 }}+\mathrm{z}_{1-2}\right)^{2} \mathrm{p} 1(1-\mathrm{p} 1)+\mathrm{p} 2(1-\mathrm{p} 2)}{(\mathrm{p} 1-\mathrm{p} 2)^{2}}$ was used, in which $\alpha=0.5, \beta=0.2$,

based on $\mathrm{p} 1=0.5$ and $\mathrm{p} 2=0.2$ (19). The sample volume for each group was obtained as 39 , where by applying $15 \%$ attrition, the final sample volume for each group was estimated as 42 individuals. Eventually, 84 patients entered the study and were assigned into control and treatment groups randomly.

At first, demographic information questionnaires including age, gender, level of education, employment status, marital status, and ethnicity were completed by the patients. The pain intensity was measured for 3 days before and after the treatment by VAS questionnaire of the samples of each group. To measure the anxiety, Spielberger scale was provided for the samples and completed by them once 1 day before the treatment and another time on the $3^{\text {rd }}$ day after the treatment.

The VAS pain visual scale is a 10 -cm ruler, whose left side is number zero (representing lack of pain) and the right side number 10 represents very severe and unbearable pain. Indeed, as we approach 10 , the patients' pain intensity is greater. Scores 1-3, 4-6, and 7-9 represent mild, moderate, and severe pain, while 10 denotes very severe pain [20]. This instrument is the most applicable pain intensity measurement tool around the world, whose reliability and validity have been confirmed in most countries of the world including Iran, and enjoys a universal validity and reliability. Research has shown that numerical gradation scale to measure pain intensity has a good validity ( $r>77 \%)$. It has also been compared with McGill scale, with a very strong correlation $(\mathrm{r}=86 \%$ ) being reported between them [21].

Spielberger questionnaire consists of 20 items, related to anxiety measurement. The minimum required scores (20) represent the absence of anxiety, while the maximum number (80) suggests a maximum level of anxiety. Scores 21-39, 40-59, and 60-80 represent mild, moderate, and severe anxiety, respectively [22]. Mahram (1994) conducted a study to standardize Spielberger test. Regarding the validity of this test, in line with the criterion sample volume (130 anxious patients as diagnosed by a psychiatrist), 130 individuals were selected randomly from the normal sample, and then to study the test validity, the mean values of evident and latent anxiety and finally the total anxiety were calculated at 0.95 and 0.99 levels separately, where the results of calculation of $95 \%$ and $99 \%$ confidence were significant [23]. The reliability for the normal group (600 people), in evident and latent anxiety scale according to Cronbach's alpha, was 0.9084 and 0.9025 . Further, this value in the criterion group (130 people) was 0.9418 . In another study, based on internal consistency of three scales, Cronbach's alpha estimation was used, which was between 70 and $78 \%$ for each scale and $73 \%$ for the entire questionnaire [23]. In addition, the high correlation of Spielberger questionnaire and Cattell anxiety test assuming suitable reliability of Cattel anxiety test is 0.93 , positive and significant. Accordingly, this questionnaire can be used to measure anxiety [24].

In the treatment group, reflexology protocol was performed following manual reflexology method by Fr Josef Eugster according to Ingham method for women samples, and with the assistance of the male researcher for men samples in the patients' room, providing confidential area and on the patients' bed [25]. The data obtained from this study were analyzed by SPSS 20, through paired t-test, Mann-Whitney, and Chi-square tests.

\section{RESULTS}

According to Table 1, the two groups did not differ significantly in terms of demographic characteristics ( $p>0.05$ ) the reflexive points of the body has been showed in Figs. 1 and 2.

Table 2 indicates that there was no significant difference in anxiety between the test and control groups before beginning of the study

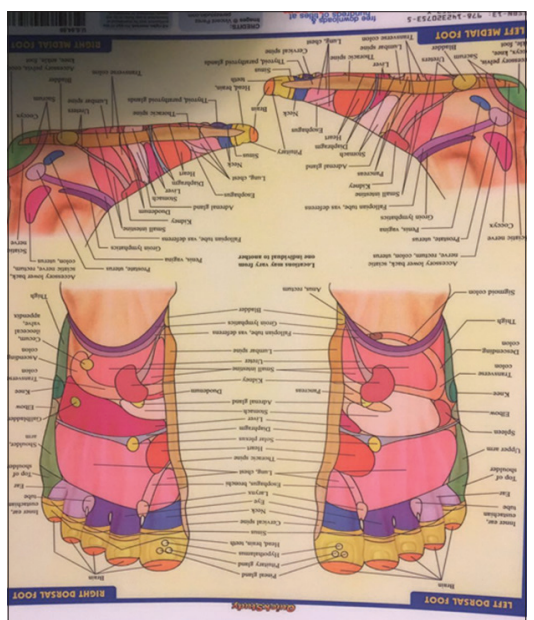

Figure 1: The effect of reflexology on intensity of pain and anxiety in patients suffering from metastatic cancer

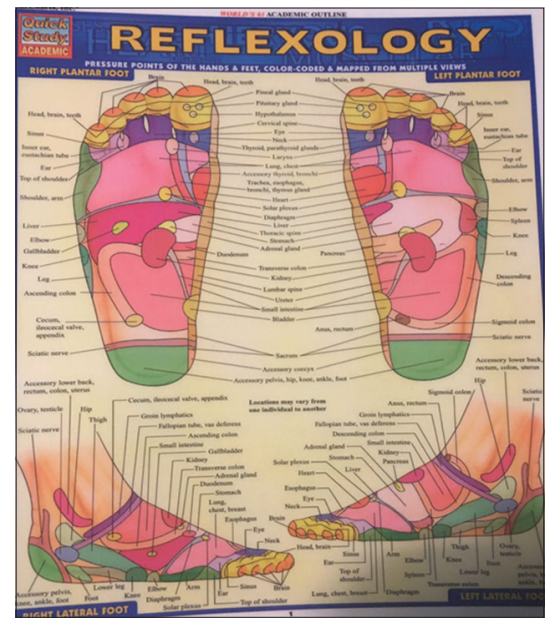

Figure 2: The effect of reflexology on intensity of pain and anxiety in patients suffering from metastatic cance 
$(\mathrm{p}=0.59)$. However, after the treatment, anxiety decreased significantly in the test group when compared to the control group $(\mathrm{p}=0.04)$. Anxiety in the test group had a significant difference before and after the treatment $(\mathrm{p}=0.008)$. However, there was no significant difference in the control group $(\mathrm{p}=0.07)$.

According to independent $t$-test results, it was found that the mean intensity of pain in the test and control groups before the treatment was not statistically significant ( $>0.05$ ). According to paired $t$-test results, it was found that there was a significant difference between the mean pain intensity before and after the treatment in the test group across 3 days $(p<0.05)$. However, no significant difference was observed between pain intensity before and after the treatment in the control group ( $\mathrm{p}>0.05)$. Further, independent $t$-test indicated that the mean pain intensity in the two groups after the treatment in the $1^{\text {st }}, 2^{\text {nd }}$, and $3^{\text {rd }}$ days differed significantly $(p<0.05)$ (Table 3$)$. Overall, the pain intensity from the $1^{\text {st }}$ to $3^{\text {rd }}$ days in the treatment group diminished far greatly than in the control group $(\mathrm{p}<0.05)$ (Table 4$)$.

According to Table 5, Chi-square test indicated that there was no significant difference among the studied individuals in terms of consuming painkiller drugs $(\mathrm{p}=0.73)$.

\section{DISCUSSION}

The findings of this research suggest that reflexology is significantly effective to mitigate the intensity of pain and anxiety in metastatic cancer patients. This is a promising outcome in using non-pharmacological nursing care that mitigates pain and anxiety for patients, especially in cancer patients. Most studies around the world suggest a positive effect of reflexology on anxiety and pain in patients suffering from different problems including different types of cancer [19, 26, 27, 28].

Table 1: Comparison of demographic characteristics of the studied patients in the test and control groups

\begin{tabular}{|c|c|c|c|}
\hline \multirow{2}{*}{$\begin{array}{l}\text { Personal } \\
\text { characteristics }\end{array}$} & \multirow{2}{*}{$\begin{array}{l}\text { Test group } \\
\mathrm{n}=42(\%)\end{array}$} & \multirow{2}{*}{$\begin{array}{l}\text { Control group } \\
\mathrm{n}=42(\%)\end{array}$} & \multirow{2}{*}{$\begin{array}{l}P \\
\text { value }\end{array}$} \\
\hline & & & \\
\hline Age & $42.50 \pm 15.139$ & $42.10 \pm 15.766$ & 0.902 \\
\hline \multicolumn{4}{|l|}{ Gender } \\
\hline Female & $19(45.2)$ & $19(45.2)$ & \multirow[t]{3}{*}{0.173} \\
\hline Male & $23(54.8)$ & $23(54.8)$ & \\
\hline \multicolumn{3}{|l|}{ Level of education } & \\
\hline Electric & $9(21.4)$ & $9(21.4)$ & \multirow{4}{*}{0.076} \\
\hline Primary & $11(26.2)$ & $11(26.2)$ & \\
\hline Guidance school & $9(21.4)$ & $10(23.8)$ & \\
\hline Diploma and above & $13(31.0)$ & $12(28.6)$ & \\
\hline \multicolumn{4}{|l|}{ Status of employment } \\
\hline Housewife & $15(35.7)$ & $17(40.5)$ & \multirow[t]{2}{*}{0.161} \\
\hline Employed & $27(64.3)$ & 25 (59.5) & \\
\hline \multicolumn{4}{|l|}{ Marital status } \\
\hline Single & $18(42.9)$ & $19(45.2)$ & \multirow[t]{2}{*}{0.170} \\
\hline Married & $24(57.1)$ & $23(54.8)$ & \\
\hline \multicolumn{4}{|l|}{ Ethnicity } \\
\hline Arab & $16(38.1)$ & $20(47.6)$ & \multirow[t]{2}{*}{0.113} \\
\hline Other & $6(14.3)$ & $8(19.0)$ & \\
\hline
\end{tabular}

Table 2: Comparison of the mean and standard deviation of anxiety before and after the treatment in the control and test groups

\begin{tabular}{llll}
\hline Level of anxiety & Test group (\%) & $\begin{array}{l}\text { Control } \\
\text { group (\%) }\end{array}$ & $\begin{array}{l}\text { P } \\
\text { value }\end{array}$ \\
\hline $\begin{array}{l}\text { Before the } \\
\text { treatment }\end{array}$ & $46.62(18.314)$ & $44.69(18.296)$ & 0.59 \\
$\begin{array}{l}\text { After the } \\
\text { treatment }\end{array}$ & $41.76(17.442)$ & $44.29(18.311)$ & \\
\begin{tabular}{l} 
P value \\
\hline
\end{tabular} & 0.008 & & - \\
\hline
\end{tabular}

Stephenson et al (2007) in their study to determine the effect of reflexology by spouse on 42 test couple groups and 44 control couple groups with 16 types of cancer, showed that a $34 \%$ decrease in pain was observed in the treatment group, while only $2 \%$ pain mitigation was seen in the control group. For anxiety also 62 and 23\% reduction in anxiety was reported for the treatment and control groups, respectively. Their findings indicated that reflexology can have a considerable role in mitigating pain and anxiety of patients [19].

The study by Shiow-Luan Tsay on gastrointestinal cancer patients as well as the research by Kahangi et al. examining the effect of feet reflexology on level of anxiety before coronary artery bypass grafting surgery on 50 volunteer patients confirms this result $[29,30]$. In the research by Briony et al., reflexology was also an effective method to mitigate stress, with the reduction being significant between the two groups [26].

In the research by Gunnarsdottir and Jonsdottir, it seems that due to influential factors such as lower sample volume of their studies in comparison to our research as well as the unequal number of people in the treatment and control groups, different results were obtained, such that in this study, the anxiety scores have been lower in all cases in the control group, when compared with the treatment group. This study indicated little evidence to support the positive effect of reflexology as an anxiety-reducing method in liver patients. In this study, nine patients entered the study as sample (four in the control group and five in the treatment group). The people in the treatment group underwent reflexology for $30 \mathrm{~min}$, while the control individuals rested during these $30 \mathrm{~min}$. Anxiety and physiological variables were measured before and after reflexology sessions once per day for more than 5 days [29].

Another finding of this research was the effect of reflexology on mitigating pain in metastatic cancer patients. According to paired t-test results, there was a significant difference between the mean intensity of pain before and after the treatment. In the research by Tsay et al., reflexology also caused a significant reduction of pain in gastrointestinal cancer patients [28].

Table 3: Comparison of the mean and standard deviation of pain intensity before and after the treatment across the 3 days in both treatment and control groups

\begin{tabular}{|c|c|c|c|}
\hline Pain intensity & $\begin{array}{l}\text { Test group } \\
(\%)\end{array}$ & $\begin{array}{l}\text { Control group } \\
(\%)\end{array}$ & $\mathbf{p}$ \\
\hline $\begin{array}{l}1^{\text {st }} \text { day before } \\
\text { the treatment }\end{array}$ & $5.86(2.46)$ & $5.48(2.50)$ & 0.45 \\
\hline $\begin{array}{l}1^{\text {st }} \text { day after } \\
\text { the treatment }\end{array}$ & $4.17(1.85)$ & $5.36(2.50)$ & \\
\hline$P$ value & $<0.0001$ & & - \\
\hline $2^{\text {nd }}$ day before & $4.88(2.27)$ & $5.90(2.18)$ & Jun-00 \\
\hline $\begin{array}{l}2^{\text {nd }} \text { day after } \\
\text { the treatment }\end{array}$ & 3.88 (2.039) & $5.67(1.946)$ & 0.001 \\
\hline$P$ value & $<0.0001$ & & - \\
\hline $\begin{array}{l}3^{\text {rd }} \text { day before } \\
\text { the treatment }\end{array}$ & $4.12(2.18)$ & $6.57(2.08)$ & 0.001 \\
\hline $\begin{array}{l}3^{\text {rd }} \text { day after } \\
\text { the treatment }\end{array}$ & $2.83(1.793)$ & $6.40(1.835)$ & 0.001 \\
\hline$P$ value & $<0.0001$ & & - \\
\hline
\end{tabular}

Table 4: Comparison of the mean and standard deviation of pain intensity in the $1^{\text {st }}$ and $3^{\text {rd }}$ days in the test and control groups

\begin{tabular}{llll}
\hline Pain intensity & Test group (\%) & Control group (\%) & $\mathbf{p}$ \\
\hline $1^{\text {st }}$ day & $5.86 .(2.46)$ & $5.48(2.50)$ & 0.003 \\
$3^{\text {rd }}$ day & $2.83(1.793)$ & $6.40(1.835)$ & Mar-00 \\
P value & 0.001 & & - \\
\hline
\end{tabular}


Table 5: Comparing consumption of painkillers before and after the treatment in the test and control groups

\begin{tabular}{lll}
\hline Painkiller consumption & Treatment group (\%) & control group (\%) \\
\hline Without change & $15(35.7)$ & $14(33.3)$ \\
Reduced consumption & $19(45.2)$ & $17(33.3)$ \\
Increased consumption & $8(19.0)$ & $11(26.2)$ \\
\hline
\end{tabular}

Similarly, in the research by Sahabi et al. on 56 patients with scoliosis undergoing spinal surgery, the samples were divided into two groups, where feet massage was performed from 2 days after the surgery for 4 consecutive days. However, in the control group, the patient's feet were only oil lubricated for $1 \mathrm{~min}$ with no pressure. The variable of pain was examined before and after the treatment, suggesting that the patients in the control group had significantly lower levels of pain across all pain dimensions, when compared with the control group [29].

In this research, there was no significant difference between the two groups in terms of consuming painkiller medications. However, in the study by Tsay et al. (2008) to determine the effectiveness of feet reflexotherapy in mitigating pain and anxiety in patients after stomach cancer surgery and blood cell cancer in Taiwan, the treatment group (massaging the digestive reflex points, i.e., upper and lower parts of the abdomen, liver, spleen, gallbladder, duodenum) had consumed significantly less painkiller. It seems that difference in massage points is the reason of different results between the two studies [28,31].

The limitations of this research affecting the extent of anxiety and pain are individual differences as well as mental and spiritual status of patients, which are of the researcher's control.

\section{CONCLUSION}

Based on the findings of this research, it can be concluded that reflexology has a positive effect on mitigating pain and anxiety of metastatic cancer patients. Furthermore, as this method is economical, does not require any special instrument, and also lacks any side effects unlike pharmacotherapy, the use of this method is recommended to mitigate pain and anxiety in patients. In addition, considering the high incidence of cancer in the society as well as the debilitating effects of pain and anxiety on quality of life of patients with cancer and the complications mentioned for chemical drugs, the necessity of developing complementary medicine, and especially, reflexology to control pain in this group of patients is strongly felt. Finally, it is suggested that further research be conducted to measure the effect of reflexology on other mental factors in patients with cancer and other diseases. It is recommended that the medical team used the findings of this research to further help cancer patients.

\section{ACKNOWLEDGMENT}

This article has been extracted from the Master's thesis of medical and surgical Nursing named Fatemeh Salari. This project approved by Ahvaz Jundishapur University of Medical Sciences with project number NCRCCD_9515.

We highly appreciate the wise presidency for financial and spiritual support. Also acknowledged the presidency of Baghaei 2 hospital and all patients who assisted us throughout performing of this research.

\section{CONFLICTS OF INTEREST}

The authors declare that there is no conflict of interest for this article.

\section{AUTHORS' CONTRIBUTION}

All authors have the same contribution at the preparation of this paper.

\section{REFERENCES}

1. World Health Organization. Global Health Observatory Data Repository. 2011. Number of Deaths (World) by Cause. Geneva: WHO;
2015.

2. Ferlay J, Soerjomataram I, Dikshit R, Eser S, Mathers C, Rebelo M, et al. Cancer incidence and mortality worldwide: Sources, methods and major patterns in GLOBOCAN 2012. Int J Cancer 2015;136:E359-86.

3. Vafajo DZ,Abedini Z, Ahmari TH, Mohamadgholizade L. Epidemiology of cancer in Qom, Iran 2008-2011. Payesh 2014;13:155-63.

4. Ghezeljeh TN, Hosseini AF. Attitudinal barriers to effective cancer pain management. J Hayat 2012;18:89-101.

5. Singh P, Chaturvedi A. Complementary and alternative medicine in cancer pain management: A systematic review. Indian J Palliative care 2015;21:105.

6. Zhou L, Liu XL, Tan JY, Yu HP, Pratt J, Peng YQ. Nurse-led educational interventions on cancer pain outcomes for oncology outpatients: A systematic review. Int Nurs Rev 2015;62:218-30.

7. Wang T, Deng R, Tan JY, Guan FG. Acupoints stimulation for anxiety and depression in cancer patients: A quantitative synthesis of randomized controlled trials. Evid Based Complement Altern Med 2016;2016:5645632.

8. Fakhar FM, Rafii F, Orak RJ. The effect of jaw relaxation on pain anxiety during burn dressings: Randomised clinical trial. Burns 2013;39:61-7.

9. Thomas K, Nicholl J, Coleman P. Use and expenditure on complementary medicine in England: A population based survey. Complement Ther Med 2001;9:2-11.

10. Donovan KA, Thompson LM, Jacobsen PB. Pain, depression, and anxiety in cancer. Handbook of Pain and Palliative Care. New York: Springer; 2013. p. 615-37.

11. Caraceni A, Portenoy R. A working group of the IASP Task Force on Cancer Pain. An international survey of cancer pain characteristics and syndromes. Pain 1999;82:74.

12. Portenoy RK, Lesage P. Management of cancer pain. Lancet 1999;353:1695-700.

13. Tehrani BS, Asgharifard H, Haghdoust A, Barghamadi M, Mohammad $\mathrm{HN}$. The use of complementary/alternative medicine among the general population in Tehran, Iran. Payesh 2008;7:355-62.

14. Lee SY, Ham YH, Ok ON, Kim EJ, Kwon IG, Hwang MS, et al. The effects of foot reflexology on peripheral neuropathy, symptom distress, anxiety and depression in cancer patients treated with Oxaliplatin. Asian Oncol Nurs 2012;12:305-13.

15. Dolatian M, Hasanpour A, Montazeri S, Heshmat R, Majd HA. The effect of reflexology on pain intensity and duration of labor on primiparas. Iran Red Cresc Med J 2011;13:475.

16. Huntley A. Reflexology in pregnancy and childbirth. Focus Altern Complement Ther 2010;15:183.

17. Stephenson N, Dalton JA, Carlson J. The effect of foot reflexology on pain in patients with metastatic cancer. Appl Nurs Res 2003;16:284-6.

18. Quattrin R, Zanini A, Buchini S, Turello D, Annunziata M, Vidotti C, et al. Use of reflexology foot massage to reduce anxiety in hospitalized cancer patients in chemotherapy treatment: Methodology and outcomes. J Nurs Manag 2006;14:96-105.

19. Stephenson NL, Swanson M, Dalton J, Keefe FJ, Engelke M. Partnerdelivered reflexology: Effects on cancer pain and anxiety. Oncol Nurs Forum 2007;34:127-32.

20. Atashi V, Mohammadi F, Dalvandi A, Abdollahi I, Kazemi R. Effect of slow stroke back massage (SSBM) on shoulder pain and hand function in patients with stroke. J Hayat 2012;18:47-56.

21. Turk DC, Melzack R. Handbook of Pain Assessment. New York, NY: Guilford Press; 2011.

22. Spielberger CD. State-Trait Anxiety Inventory. Palo Alto, CA: Consulting Psychologists Press: Wiley Online Library; 2010.

23. Mahram B. Standardize of Speilberger test in Mashhad City. Unpublished MSc [Thesis] Tehran: Alameh Tabatabaie Univercity; 1994.

24. Esmaeili M. A survey of the influence of murita therapy on reducing the rate of anxiety in clients of counseling centers. Research in Clinical Psychology and Counseling 2011;1:15-30.

25. Caraceni A. Modern insights in the nature and treatment of cancer pain: Focus on opioids. Euro J Hosp Pharm Sci Pract 2012;19:29-30. 
26. Hudson BF, Davidson J, Whiteley MS. The impact of hand reflexology on pain, anxiety and satisfaction during minimally invasive surgery under local anaesthetic: A randomised controlled trial. Int J Nurs Stud 2015;52:1789-97.

27. Quinn F, Hughes CM, Baxter G. Reflexology in the management of low back pain: A pilot randomised controlled trial. Complement Ther Med 2008;16:3-8

28. Tsay SL, Chen HL, Chen SC, Lin HR, Lin KC. Effects of reflexotherapy on acute postoperative pain and anxiety among patients with digestive cancer. Cancer Nurs 2008;31:109-15.
29. Gunnarsdottir TJ, Jonsdottir H. Does the experimental design capture the effects of complementary therapy? A study using reflexology for patients undergoing coronary artery bypass graft surgery. J Clin Nurs 2007; 16:777-85.

30. Reddy DR, Kalyani G, Pradeep K, Asif MD, Kartheek D, Gangabhavani $\mathrm{M}$. The survey of cancer patients in the region of Guntur: Based on hospital registry. Int J Pharm Pharm Sci 2017;9:228-32.

31. Kaivani M, Sepahi S, Azima S, Emamghoreishi M, Asadi N, Haghpanah S. The effects of olive leaf extract ointment on pain intensity and early maternal complications in primiparous women. Int J Pharm Pharm Sci 2017;9:31-4. 